\title{
Observations of the diurnal cycle of outgoing longwave radiation from the Geostationary Earth Radiation Budget instrument
}

Article

Published Version

Comer, R. E., Slingo, A. and Allan, R. P. (2007) Observations of the diurnal cycle of outgoing longwave radiation from the Geostationary Earth Radiation Budget instrument. Geophysical Research Letters, 34 (2). L02823. ISSN 0094-8276 doi: https://doi.org/10.1029/2006GL028229 Available at https://centaur.reading.ac.uk/865/

It is advisable to refer to the publisher's version if you intend to cite from the work. See Guidance on citing.

Published version at: http://dx.doi.org/10.1029/2006GL028229

To link to this article DOI: http://dx.doi.org/10.1029/2006GL028229

Publisher: American Geophysical Union

All outputs in CentAUR are protected by Intellectual Property Rights law, including copyright law. Copyright and IPR is retained by the creators or other copyright holders. Terms and conditions for use of this material are defined in the End User Agreement. 


\section{CentAUR}

Central Archive at the University of Reading

Reading's research outputs online 


\title{
Observations of the diurnal cycle of outgoing longwave radiation from the Geostationary Earth Radiation Budget instrument
}

\author{
Ruth E. Comer, ${ }^{1}$ Anthony Slingo, ${ }^{1}$ and Richard P. Allan ${ }^{1}$ \\ Received 20 September 2006; revised 7 November 2006; accepted 21 December 2006; published 30 January 2007.
}

[1] The Geostationary Earth Radiation Budget instrument on Meteosat-8, located over Africa, provides unprecedented temporal sampling ( $\sim 17$ minutes) of the broadband emitted thermal and reflected solar radiances. We analyse the diurnal cycle of the outgoing longwave radiation (OLR) fluxes derived from the thermal radiances for July 2006. Principal component (PC) analysis separates the signals of the surface temperature response to solar heating and of the development of convective clouds. The first two PCs explain most of the OLR variations: PC1 (surface heating) explains $82.3 \%$ of the total variance and PC2 (cloud development) explains $12.8 \%$ of the variance. Convection is initiated preferentially over mountainous regions and the cloud then advects downstream in the ambient flow. Diurnal variations are much weaker over the oceans, but a coherent signal over the Gulf of Guinea suggests that the cloudiness is modulated by the diurnally varying contrast between the Gulf and the adjacent land mass. Citation: Comer, R. E., A. Slingo, and R. P. Allan (2007), Observations of the diurnal cycle of outgoing longwave radiation from the Geostationary Earth Radiation Budget instrument, Geophys. Res. Lett., 34, L02823, doi:10.1029/2006GL028229.

\section{Introduction}

[2] The diurnal cycle of solar radiation represents one of the climate system's most significant modes of forcing. The response to this forcing provides information on the physical processes acting at the surface and in the atmosphere, which must be represented accurately in weather and climate prediction models. The outgoing longwave radiation (OLR) represents the cooling of the planet to space and also provides a powerful diagnostic of the surface and atmospheric response to the diurnal solar forcing. Studies of the diurnal cycle of the OLR measured by satellites have therefore been made for many years, both to understand these physical processes and to evaluate models (see Yang and Slingo [2001] for a review). Many studies have analysed the OLR derived from narrow-band sensors on operational weather satellites in both sun-synchronous polar and geostationary orbits, often averaging several years of data to improve the statistics [e.g., Gube, 1982; Yang and Slingo, 2001; Smith and Rutan, 2003; Nowicki and Merchant, 2004]. Smith and Rutan [2003] used five years of data from the Earth Radiation Budget Satellite (ERBS) [Barkstrom et al., 1989]. This carried broad-band sensors, providing a more direct measure of the OLR,

\footnotetext{
${ }^{1}$ Environmental Systems Science Centre, University of Reading, Reading, UK.
}

Copyright 2007 by the American Geophysical Union. 0094-8276/07/2006GL028229\$05.00 although the orbit took 72 days to precess through all local solar times.

[3] Geostationary satellites clearly provide superior temporal sampling of OLR and data from multiple satellites can be combined to yield near-global coverage [Yang and Slingo, 2001; Tian et al., 2004]. Even a limited data record from a single geostationary satellite can be used to study short-term variations over specific areas: for example, Slingo et al. [2004] analysed only 3 months of narrow-band radiances from Meteosat-7. This was made possible by the improved time resolution of 30 minutes compared with the 3 hourly data used by Yang and Slingo [2001].

[4] The new Geostationary Earth Radiation Budget (GERB) instrument on the Meteosat- 8 satellite provides the first broad-band radiation budget measurements from geostationary orbit [Harries et al., 2005]. The satellite is positioned at $0^{\circ}$ latitude, $3.5^{\circ} \mathrm{W}$ longitude, enabling analysis of the radiation budget over Africa and surrounding regions. The unprecedented temporal resolution of approximately 17 minutes enables a higher resolution investigation of the diurnal cycle of the OLR than has previously been possible. In this study, we analyse GERB data for July 2006. Following Smith and Rutan [2003], Principal Component (PC) analysis is used to investigate the diurnal cycle and the strengths and weaknesses of this approach are demonstrated. In general, it is seen that the first PC represents the land surface temperature response to the solar heating and the second PC represents the cloud response. The majority of the diurnal variations in the data can be described with just these first two PCs. The significance of topography for affecting the development of convective cloud is also evident. In some regions, however, there exists a more complex interaction between the radiative processes and moist dynamics, so this simple picture breaks down.

\section{Data}

[5] This study uses one month of the Edition 1 release of the GERB OLR data for July 2006 in the ARG flux product. The ARG data have a time resolution of approximately 17 minutes. The ARG grid has 256 by 256 pixels on an equi-angular projection onto the Earth's surface, centered at $0^{\circ}$ latitude, $0^{\circ}$ longitude and has a nominal nadir resolution of $50 \mathrm{~km}$. The outgoing longwave radiances have an estimated absolute accuracy of $0.96 \%$, while the angular modelling introduces an additional error in the inferred outgoing longwave irradiance, estimated to be $5 \mathrm{Wm}^{-2}$ [Slingo et al., 2006]. Since the maximum OLR value in the data used here is about $390 \mathrm{Wm}^{-2}$, the error should be less than $9 \mathrm{Wm}^{-2}$. In the present study the analysis is restricted to those data with viewing zenith angles of less than 70 degrees. The data are interpolated onto a regular latitude-longitude grid with a resolution of 0.556 degrees in latitude and 
o)

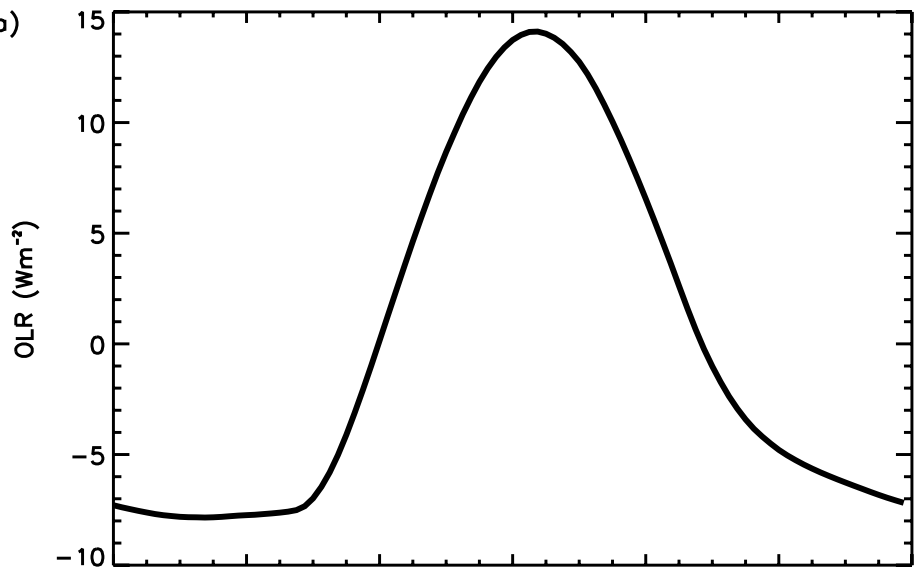

c)

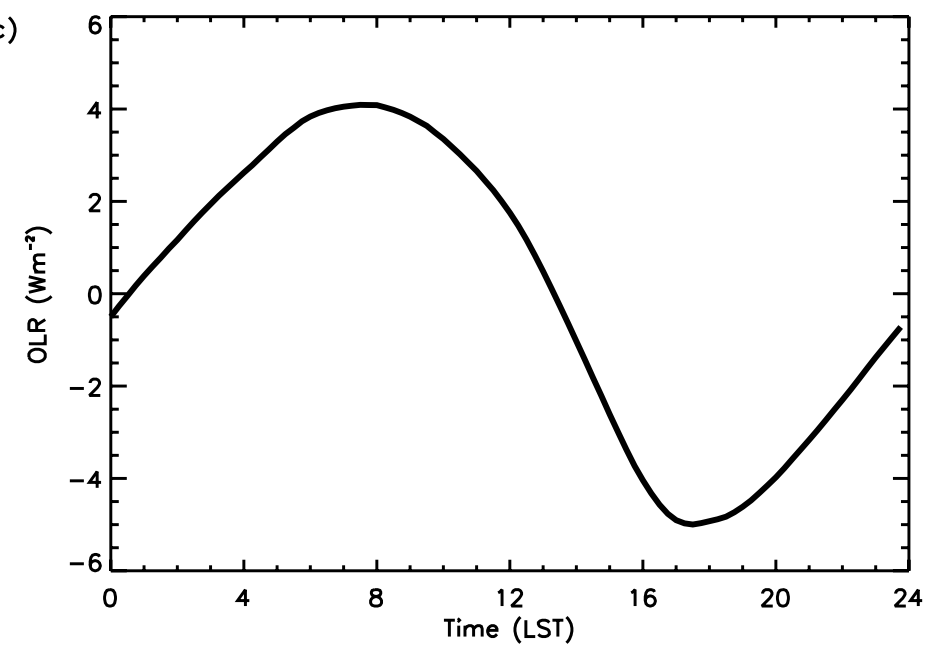

b)

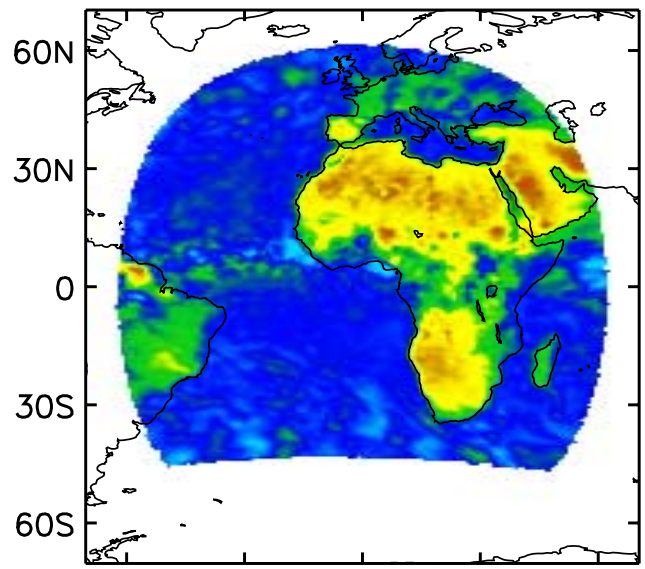

d)

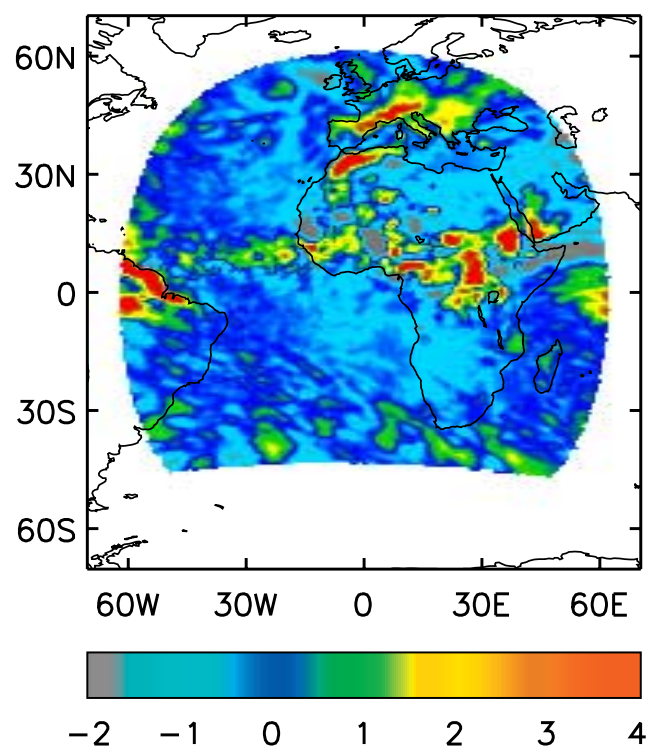

Figure 1. (a, c) First two principal components of GERB data for July 2006 together with (b, d) their respective empirical orthogonal functions.

0.833 degrees in longitude. This interpolation facilitates comparisons we have been making with the Met Office global forecast model [Allan et al., 2005], as well as simplifying the current analysis method (see next section). The analysis here is also limited to those cells in the new grid which have data available for all times of day $(24,827$ in total). Very similar results were obtained using preliminary GERB BARG data for July 2004 [Comer et al., 2006], but the more recent data are shown here because they have been released into the public domain. Further details of the GERB instrument and data processing are provided by Harries et al. [2005] and of the Meteosat-8 satellite by Schmetz et al. [2002].

\section{Method}

[6] Empirical orthogonal functions (EOFs) and principal components (PCs) are calculated to describe respectively spatial and temporal variations in the data. The first PC describes the dominant signal in the data, having maximum possible variation. Each subsequent PC describes the maximum variation of the data set after that of the preceding PCs has been removed. Each PC has a corresponding EOF, which shows where in the GERB view the variation associated with that PC is significant.

[7] To create an average diurnal cycle the data are first linearly interpolated to every fifteen minutes, so that monthly means can be calculated for 96 regular intervals throughout the day. This diurnal cycle for July 2006 is then interpolated to local solar time (LST). The PCs and EOFs are computed following the method described by Smith and Rutan [2003]. For each cell in the GERB field of view the overall mean is removed to provide a matrix of deviations, $\mathbf{X}$, with a row for each of the 96 times of day and a column for each cell $(24,827$ columns in total). Each column of the matrix $\mathbf{X}$ is multiplied by the square root of the area weight (the cosine of the latitude, $\theta$ ) of the cell and a 96 by 96 covariance matrix is formed:

$$
\boldsymbol{\Gamma}=\frac{\mathbf{X} \operatorname{diag}(\cos \theta) \mathbf{X}^{\mathbf{T}}}{\Sigma \cos \theta},
$$

where $\operatorname{diag}(\cos \theta)$ is the diagonal matrix of area weights and $\Sigma \cos \theta$ is the sum of the area weights over the whole GERB view. The PCs $\left(\mathbf{c}_{i}, i=1, \ldots, 96\right)$ are the eigenvectors of this 

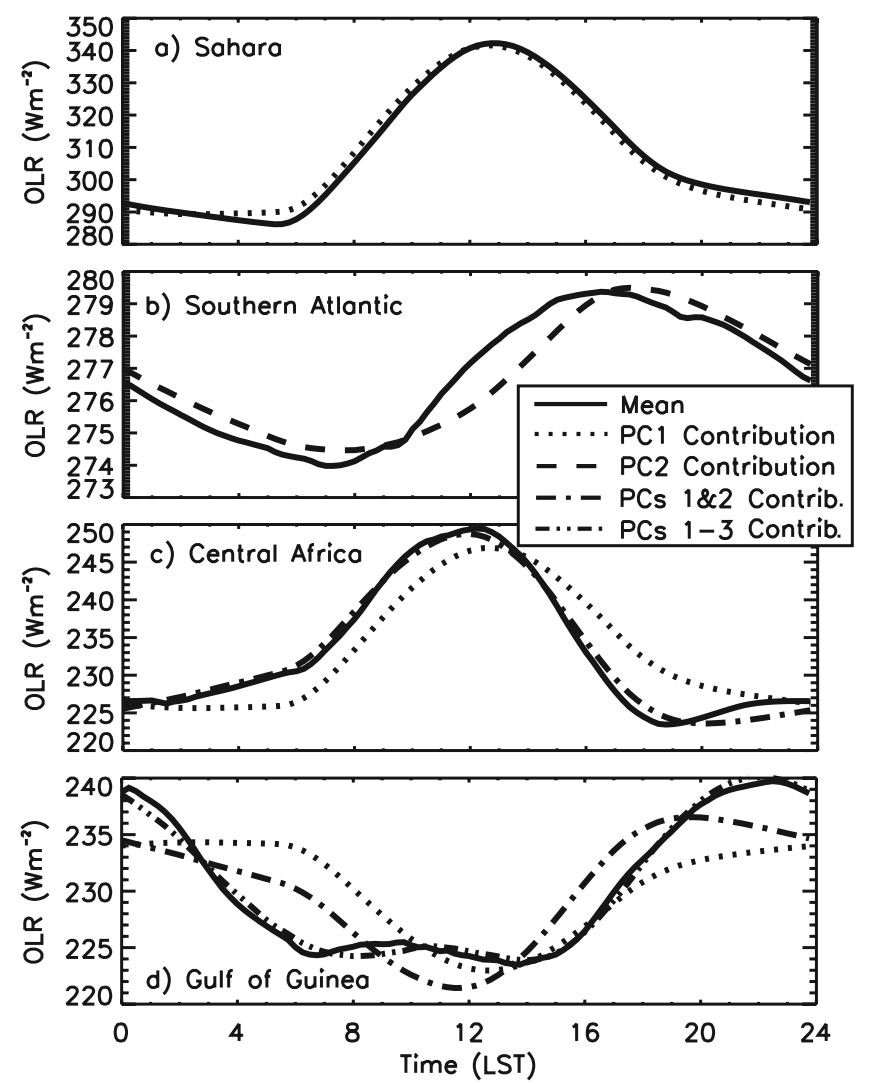

Figure 2. Comparisons of mean diurnal cycles (solid lines) with contributions from the principal components for (a) Sahara $\left(20^{\circ}-30^{\circ} \mathrm{N}, 10^{\circ}-20^{\circ} \mathrm{E}\right)$; (b) Southern Atlantic $\left(10^{\circ}-20^{\circ} \mathrm{S}, 0^{\circ}-10^{\circ} \mathrm{W}\right)$; (c) Central Africa $\left(5^{\circ} \mathrm{S}-10^{\circ} \mathrm{N}\right.$, $\left.22^{\circ}-35^{\circ} \mathrm{E}\right)$; and (d) Gulf of Guinea $\left(2^{\circ}-6^{\circ} \mathrm{N}, 2^{\circ}-8^{\circ} \mathrm{E}\right)$.

covariance matrix, arranged according to descending eigenvalues $\left(\lambda_{i}\right)$, and normalised so that $\left|\mathbf{c}_{i}\right|$ for each is equal to the square root of its eigenvalue $\lambda_{i}$. The relevant EOF $\left(\mathbf{a}_{i}\right)$ for each PC is calculated from the PC and the data matrix:

$$
\mathbf{a}_{i}=\frac{\mathbf{X}^{\mathbf{T}} \mathbf{c}_{i}}{\lambda_{i}}
$$

[8] The study here differs from that of Smith and Rutan [2003] in that the land and ocean cells are not separated out, but the domain is considered as a whole. The separation does not significantly affect the results and, as shown later, both land and ocean variations are well represented.

\section{Results}

[9] Figure 1 shows the diurnal variations described by the first two PCs and their associated EOFs. The first PC (Figure 1a) describes $82.3 \%$ of the variance in the data and arises from the response of the land surface temperature (and hence the OLR) to the solar heating. PC1 shows nocturnal cooling with a minimum around dawn, followed by a rapid response to the solar heating up to a maximum at about 1300 Local Solar Time (LST). This lag of the solar heating by approximately one hour is primarily due to the finite heat capacity of the surface, but may also be influ- enced by atmospheric and surface feedbacks to the heating [Yang and Slingo, 2001]. After the maximum, the temperature declines as the solar input decreases to sunset, after which cooling continues more slowly until dawn. This attribution of PC1 to surface heating was also found by Smith and Rutan [2003], although they noted that their first PC was "surprisingly symmetric" and required the addition of their second PC to produce the expected asymmetric behaviour. This behaviour is wholly described by our first PC, which perhaps illustrates the sensitivity of this analysis technique to the particular dataset employed; the curve was not made symmetric by degrading the data to hourly resolution or restricting the analysis to land regions.

[10] The first EOF (Figure 1b) shows that PC1 is largest over the deserts, which is where the diurnal surface temperature variations are greatest. Over the Saharan and Arabian deserts, the peak to trough amplitude in the OLR approaches $90 \mathrm{Wm}^{-2}$. The amplitude over the Kalahari is at most around $60 \mathrm{Wm}^{-2}$, because of the smaller insolation and surface heating in the Southern winter. Since surface solar heating over the desert is primarily responsible for the diurnal changes in the OLR, the mean diurnal cycle of the OLR here is nearly identical to that of PC1. This is illustrated for the Sahara in Figure 2a. Over the oceans, the amplitude of EOF1 is very small and generally not significant. There are coherent negative signals over the Gulf of Guinea and off the West coast of Africa, which are discussed later. Features in the Southern hemisphere on both EOF maps are due to episodic travelling synoptic systems that alias onto the diurnal PCs.

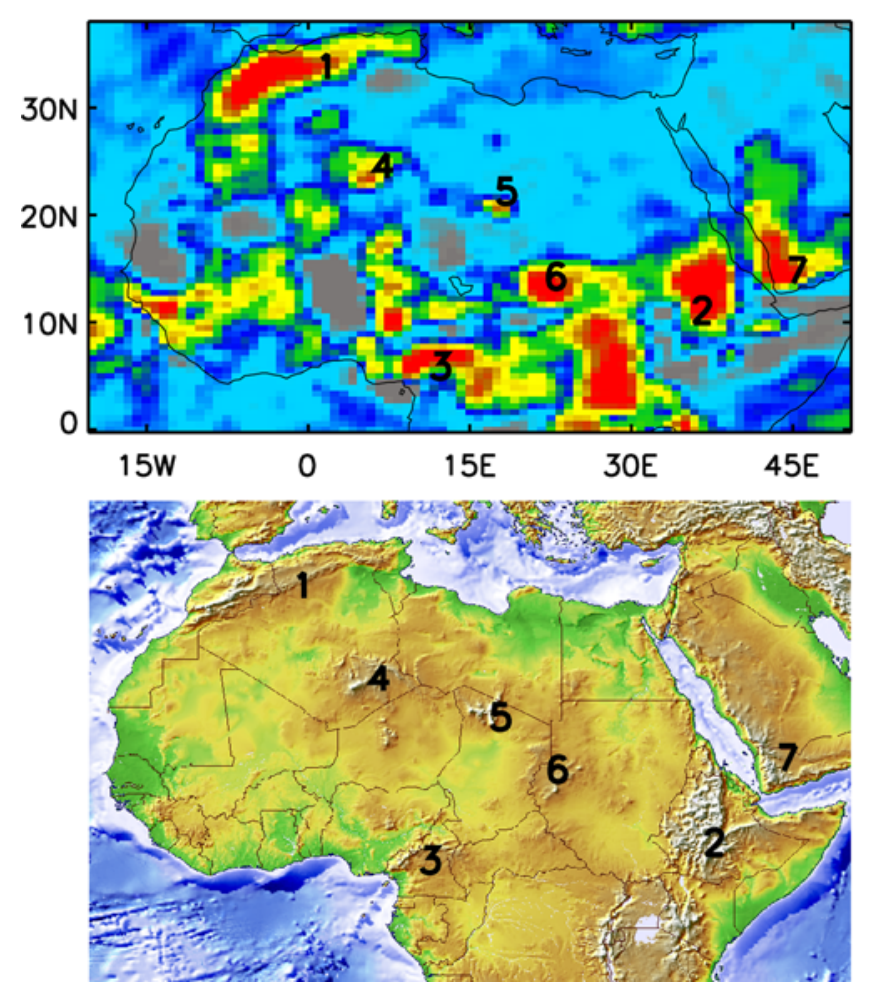

Figure 3. Comparison of the second empirical orthogonal function with topographical features in North Africa and the Arabian Peninsula (topographical map courtesy of UNEP/ GRID-Arendal, http://globalis.gvu.unu.edu/). 
[11] The diurnal cycle in clouds shows up clearly in the second principal component, PC2 (Figure 1c). This describes $12.8 \%$ of the diurnal variance, giving a total of over $95 \%$ of the variance explained by just the first two PCs. The main OLR signal in EOF2 is from convective cloud over land. The cloud is triggered by the surface heating (represented by the first PC) just after dawn and as it grows to a maximum extent at about 1700-1800 LST the OLR is forced to decrease as the cloud tops grow to higher, colder levels. After this time, the cloud gradually dissipates and the OLR increases again [Yang and Slingo, 2001, and references therein]. The second EOF (Figure 1d) also shows that many of the strongest signals for the convective cloud are found over mountainous regions. This is illustrated further in Figure 3, which shows a comparison of the second EOF with a map of the topography in North Africa and the Arabian Peninsula. Peaks in EOF2 are seen to be associated with (1) the Atlas mountains, (2) the Ethiopian and (3) Cameroon highlands, (4) the Hoggar, (5) Tibesti and (6) Marra plateau, (7) the Yemeni highlands and several other smaller mountain ranges. This link between the topography and the OLR was also noted by Yang and Slingo [2001] in their Fourier analysis of narrowband radiances. However, the present EOF analysis shows the influence much more clearly because the cloud signal is almost entirely contained in EOF2.

[12] Two bands are visible over North-East Brazil in Figure $1 \mathrm{~d}$ which are also due to convective cloud. These were apparent in the analysis by Garreaud and Wallace [1997] of nine years of data from the International Satellite Cloud Climatology Project (ISCCP). The coastal band is a convective system, probably formed by the interaction of land-sea breezes with the mean easterly flow [Kousky, 1980]. This system propagates inland and is reactivated the following evening to form the second distinctive band [Garreaud and Wallace, 1997; Cohen et al., 1995]. The positive signal in EOF1 (Figure 1b) in this region is slightly southwest of the coastal band in EOF2 and is likely to correspond to the maximum in convective cloud as it passes over that area overnight. Yang and Slingo [2001] pointed out that the phase of the diurnal harmonic becomes later in LST as mesoscale convective systems move away from their source (usually westward in the tropics). This was reproduced in a Fourier analysis of the GERB data (not shown here), where the time of the maximum of the diurnal harmonic changes from around 0600 LST to 1100 LST over both North-East Brazil and the Ethiopian highlands.

[13] EOF2 also shows negative values over the SouthEast tropical Atlantic, which are not evident in the SouthWest Atlantic trade cumulus zone. These values are due to low-level stratocumulus cloud, which is at its maximum extent (minimum OLR) just before dawn and is dissipated by solar heating, with a minimum extent (maximum OLR) in the late afternoon [Ciesielski et al., 2001]. The overall impact on the OLR is small (approximately $5 \mathrm{Wm}^{-2}$ ), because the cloud top is only slightly cooler than the ocean. Figure $2 \mathrm{~b}$ shows that the variation described by EOF2 is largely responsible for the mean diurnal cycle of the OLR in this region.

[14] Using the two most significant principal components, it is possible to build up a reasonably accurate picture of the diurnal variations as a whole over most regions. For example, Figure $2 \mathrm{c}$ shows the mean variation over central Africa. The mean diurnal cycle is shown to have an earlier maximum than given by $\mathrm{PC} 1$. The combined contribution from the first two PCs provides a much closer fit to the overall mean. This illustrates the value of principal component analysis in combination with additional information for representing physical variations. Over this region of Africa, PC1 explains the majority of the variation in the OLR, meaning that surface heating is dominant. However, the significant convective cloud signal in this area [Nowicki and Merchant, 2004] leads to PC2 moving the overall peak of the diurnal cycle to earlier in the day and producing a much faster decrease after noon as the cloud grows.

[15] As mentioned earlier, the first EOF has some small areas of negative values around the coast of Africa. Since diurnal changes in ocean surface temperature are small [Weller and Anderson, 1996], the EOF1 signal here does not relate directly to the surface heating response. Instead, it is likely to relate to cloud development that is influenced by the adjacent heating of land regions. It can be seen from Figure $2 \mathrm{~d}$ that the mean variation over the Gulf of Guinea does indeed have a significant daytime minimum and midnight maximum, but the shape of the curve is not similar to PC1. In fact the second and third PCs are both required to describe the variation. Plotting the mean OLR against local time over a series of days (not shown here) reveals that there is a regular daytime minimum, so this is not the result of a large synoptic system affecting the overall mean. The exact time of the minimum varies from day to day and tends to fall between 0400 LST and 1600 LST. Daytime maxima in cloud amount both in the Gulf of Guinea and off the west coast of Africa have been noticed before [Duvel, 1989; Desbois et al., 1988]. Desbois et al. suggested that this daytime maximum in cloud is forced by land-sea breeze effects.

[16] The feature in the Gulf of Guinea is one illustration of the limitations of EOF analysis for identifying physical processes. While the OLR variation can generally be attributed to surface temperature variation (PC1) and cloud variation (PC2), there are areas where anomalies do not follow this interpretation. As well as the Gulf of Guinea region, the North-East Brazil region discussed above has a significant signal in EOF1 that is not directly due to surface heating. The variation apparent here is likely due to convective cloud (and therefore a cold anomaly) passing over the region at night, rather than a warm surface anomaly during the day. Negative signals over West Africa in EOF2 correspond to the westward advection of convective cloud after a lag of approximately twelve hours.

\section{Summary and Further Work}

[17] This first look at the diurnal cycle in GERB data highlights the effectiveness of high temporal resolution satellite data for exploring the diurnal cycle in the atmosphere and at the land surface. Following Smith and Rutan [2003], we have shown that principal component analysis provides a powerful tool for analysing the diurnal cycle, because the physical signals of surface heating and cloud response in EOFs 1 and 2 are clearly identified. There is a distinct orographic influence on the diurnal development of cloudiness over Africa. A coherent diurnal cycle of 
convection over the northern coast of Brazil and the Gulf of Guinea is also found, suggesting a modulation by the diurnally varying contrast between land and ocean.

[18] This quantitative assessment of OLR variations can readily be expanded using additional atmospheric observations, reanalyses and models. A specific application involves water vapour and its diurnal cycle in relation to that of clouds. Water vapour channel radiances from the SEVIRI imager [Schmetz et al., 2002] are currently being analysed to study variations in upper tropospheric humidity. The methodology described in the present study can also be used to evaluate diurnal variations in numerical weather prediction and climate models, especially when the models have high spatial resolution.

[19] Acknowledgments. The GERB data were obtained from the GERB Ground Segment Processing System (GGSPS) at Rutherford Appleton Laboratory. We thank fellow members of the GERB International Science Team for comments and suggestions throughout the study. Comments from C. Merchant and an anonymous reviewer helped to improve the final version of the manuscript. R.E. Comer was funded by a RETF/ESSC postgraduate grant.

\section{References}

Allan, R. P., A. Slingo, S. F. Milton, and I. Culverwell (2005), Exploitation of Geostationary Earth Radiation Budget data using simulations from a numerical weather prediction model: Methodology and data validation, J. Geophys. Res., 110, D14111, doi:10.1029/2004JD005698.

Barkstrom, B., et al. (1989), Earth Radiation Budget Experiment (ERBE) archival and April 1985 results, Bull. Am. Meteorol. Soc., 70, 12541262.

Ciesielski, P., W. Schubert, and R. Johnson (2001), Diurnal variability of the marine boundary layer during ASTEX, J. Atmos. Sci., 58, 23552376.

Cohen, J., M. S. Dias, and C. Nobre (1995), Environmental conditions associated with Amazonian squall lines: A case study, Mon. Weather Rev., 123, 3163-3174.

Comer, R. E., A. Slingo, and R. P. Allan (2006), The diurnal cycle observed by Meteosat- 8 and simulated by a climate model, paper presented at EUMETSAT Meteorological Satellites Conference, Finnish Meteorol. Inst., Helsinki, 12-16 Jun.
Desbois, M., T. Kayiranga, B. Gnamien, S. Guessous, and L. Picon (1988), Characterization of some elements of the Sahelian climate and their interannual variations for July 1983, 1984 and 1985 from the analysis of METEOSAT ISCCP data, J. Clim., 1, 867-904.

Duvel, J. (1989), Convection over tropical Africa and the Atlantic Ocean during northern summer. part I: Interannual and diurnal variations, Mon. Weather Rev., 117, 2782-2799.

Garreaud, R., and J. Wallace (1997), The diurnal march of convective cloudiness over the Americas, Mon. Weather Rev., 125, 3157-3171.

Gube, M. (1982), Radiation budget parameters at the top of the Earth's atmosphere derived from METEOSAT data, J. Appl. Meteorol., 21, $1907-1921$.

Harries, J., et al. (2005), The Geostationary Earth Radiation Budget (GERB) project, Bull. Am. Meteorol. Soc., 86, 945-960.

Kousky, V. (1980), Diurnal rainfall variation in northeast Brazil, Mon. Weather Rev., 108, 488-498.

Nowicki, S. M. J., and C. J. Merchant (2004), Observations of diurnal and spatial variability of radiative forcing by equatorial deep convective clouds, J. Geophys. Res., 109, D11202, doi:10.1029/2003JD004176.

Schmetz, J., P. Pili, S. Tjemkes, D. Just, J. Kerkman, S. Rota, and A. Ratier (2002), An introduction to Meteosat Second Generation (MSG), Bull. Am. Meteorol. Soc., 83, 977-992.

Slingo, A., K. Hodges, and G. Robinson (2004), Simulation of the diurnal cycle in a climate model and its evaluation using data from Meteosat 7, Q. J. R. Meteorol. Soc., 130, 1449-1467.

Slingo, A., et al. (2006), Observations of the impact of a major Saharan dust storm on the atmospheric radiation budget, Geophys. Res. Lett., 33, L24817, doi:10.1029/2006GL027869.

Smith, G., and D. Rutan (2003), The diurnal cycle of outgoing longwave radiation from Earth Radiation Budget Experiment measurements, J. Atmos. Sci., 60, 1529-1542.

Tian, B., B. J. Soden, and X. Wu (2004), Diurnal cycle of convection, clouds, and water vapor in the tropical upper troposphere: Satellites versus a general circulation model, J. Geophys. Res., 109, D10101, doi:10.1029/2003JD004117.

Weller, R., and S. Anderson (1996), Surface meteorology and air-sea fluxes in the western equatorial Pacific warm pool during the TOGA coupled ocean-atmosphere response experiment, J. Clim., 9, 19591990.

Yang, G.-Y., and J. Slingo (2001), The diurnal cycle in the tropics, Mon. Weather Rev., 129, 784-801.

R. P. Allan, R. E. Comer, and A. Slingo, Environmental Systems Science Centre, University of Reading, Harry Pitt Building, 3 Earley Gate, Whiteknights, Reading RG6 6AL, UK. (rec@mail.nerc-essc.ac.uk) 